Page Title

Statement by Kathleen Shannon Distributed at the April 211998 senate meeting

- - FOR DISCUSSION ONLY - - -

\title{
Faculty Responsibilities:
}

Given that many administrators feel that faculty time is an infinite well from which they can dip repeatedly without ever running out and that the unofficial list of faculty responsibilities seems to be growing without bound (items are continually added and nothing is ever removed) perhaps the time has come to clearly articulate what faculty responsibilities are. If we are to do that then there are a number of issues that need to be resolved first. For example is it a good idea to say that every faculty member should attend every graduation and convocation or would it be more reasonable to say that each department must ensure that it is adequately represented at every graduation and convocation. Clearly we do not want or need every faculty member to be doing exactly the same or even very similar sets of things. How can we come closest to ensuring that all of the different responsibilities which are necessary to the accomplishment of the University mission are rewarded in a manner that is commensurate with the effort which they require? At present some people who enable others to do flashier or more visible things seem not to be appreciated or rewarded. The Dean's council has provided us with a reasonable starting point for discussion (prejudicial citizenship language aside). I would suggest that we discuss the individual items on the list to decide whether they truly should be expected of all faculty. We also need to see if there are items that are missing from the list and start to determine how we might go about creating a document that captures faculty workload in a reasonably comprehensive way but also defines ways of determining what constitutes an appropriate subset for an individual to accomplish. 